\title{
Role of Social Media in Shaping Public Risk Perception during COVID-19 Pandemic: A Theoretical Review
}

\author{
${ }^{1}$ Diana Tsoy, ${ }^{2}$ Tanin Tirasawasdichai, ${ }^{3}$ Konstantin Ivanovich Kurpayanidi \\ ${ }^{1}$ Shanghai Jiao Tong University, Shanghai, China \\ ${ }^{2}$ School of Media and Communication, Shanghai Jiaotong University; Shanghai, 200240, China \\ ${ }^{3}$ Fergana Polytechnic Institute, Fergana, Uzbekistan
}

\begin{abstract}
Various national and global media outlets have daily reports and updates concerning the Coronavirus pandemic, reporting on the number of infected, quarantined, hospitalized and deaths, as well as new policy measures and restrictions introduced and implemented. While traditional media still plays a significant role in shaping risk perception, social media can be considered even more influential. The aim of the paper is to reflect on the impact of social media exposure during COVID-19 on perceived threat and efficacy by the implementation of PMT theory through EPPM model. We point to the interaction between the EPPM model and SDT (self-determination) theory in 'Stay at home' behaviour. The paper ponders on the usefulness of social media in achieving better preventive results among people. Social media platforms' immense potential in forming peoples' opinions and risk perceptions calls for crisis communication management on the part of governments, Security and Reconnaissance staff, and policymakers. Joining forces with leading scientists from various domains, such as epidemiology, governance, economy, and psychology, should create strong, potent and persuasive content tailored to fit the social media format and healthcare protection campaigns. The news should deliver the message clearly and reliably, following the suggestions of the EPPM model standard. In the instance of the 'Stay at home' campaign that promotes abiding with social distancing recommendations, experts should combine appropriate images, data and information according to fear-driving model, and provide reliable guidelines concerning protective measures citizens can take to ensure safety. Apart from freight inciting strategy, propaganda should focus on educating and emphasizing the effectiveness of complying with the norm.
\end{abstract}

Keywords: COVID-19 pandemic, Fear of COVID-19, Social media and COVID-19, EPPM theory, Cultivation theory and social media, Stay at home

\section{Introduction}

COVID-19 is the most "discussed" disease that ever happened to human beings. The features of COVID-19 can be accounted for its propensity to spread via air, absence of the verified cure and lack of medical equipment for mechanical ventilation, masks and protective gear at the beginning of the pandemic period. Its similarity with usual cold and flu makes it hard to distinguish, and infected persons can easily misjudge it to be the flu. With the current development of transportation and globalization, the virus's spread was far quicker than any other known disease before. The widespread virus had adverse effects on all levels of society, from sustainability of enterprises (Obrenovic et al. , 2020) to mental health of individuals (Godinic et al. , 2020). Via social media sites, people could find messages concerning disease risk as well as its interpretation. Media can change the way people think about the dangers since individuals can process the data relevant to the risk (Chong \& Choy, 2018). The latest pandemic is also called "infodemic" (WHO, 2020), due to massive information overflow about the virus. And the most significant portion of COVID-19's fame is due to the particular attention of media, especially social media. Generation $\mathrm{Z}$ and even earlier generations are familiar with the Internet, new technology and social media. Especially young people are capable not only to consume but also produce social media content. It can be used for the informative purpose to create awareness among friends, followers, and partially it can also be done for engaging with the audience, discussion and exchange of knowledge. 
There has been very little research carried out on the response of the public to outbreaks of diseases. The study aims primarily to determine a set of specific actions and messages state and private organizations alike must engage in to maintain preventive behaviours in the middle of the health crisis, particularly the COVID-19. Despite the rising popularity of social media during the course of a pandemic, the real effects on public reaction, risk perception, and protection measures have not been thoroughly investigated. Although epidemics' peculiarity is uncertainty within a society, some people do not always obey the new rules and instructions and refuse to sustain preventive actions. For this reason, the current paper relevant literature and theoretical frameworks that can be used to develop new methods of endorsing preventive measures through the use of social media. This research focuses on the impact of social media exposure during COVID-19 on perceived threat and efficacy by the implementation of PMT theory through EPPM model. We point to the interaction between the EPPM model and SDT (self-determination) theory in 'Stay at home' behaviour. The paper ponders on the usefulness of social media in achieving better preventive results among people. We expect the exploration will help governments and policymakers achieve better and faster communication with people. Facing such force critical situation like a pandemic, natural disasters, time is crucial. It is essential to use the correct media channel to ensure peoples' safety. Furthermore, it is vital to understand the psychological condition of people under abnormal situations.

\section{COVID-19 Pandemic and Social Media}

Social media provides a platform for exchanging opinions, convictions, information and stances, and it can be used to raise a concern and prompt questions regarding emerging situations. Companies are often turning toward social media channels to raise awareness of their services, relying on users to repost and share relevant information (Silvia, 2019), and ultimately increase financial performance (Etim et al., 2019). Social media metrics can show the real results of promoted campaigns such as engagement, conversion, response rate, and reach. The assumption is, accounting for the analytic benefits, that if brands consider social media to be the best platform for advocating their mission, policymakers can use health awareness among the population and promote protective behaviours. Several countries focused on such an approach. For instance, in Sweden, campaigns were launched on social media educating on health hygiene, social distancing and stay-at-home recommendations. The information was shared in official Swedish language and in English, Russian, and Arab. Even though the metrics such as reach can be traced, it is hard to predict whether the person followed the instructions or not, whether it was due to promoted campaigns and banners from the government side or whether it was due to the impact of all the news, discussions in social media.

When it comes to interpretation function - mass media should provide ethical and objective information. Apart from providing access to existing data, new media helps create new knowledge based on the exchange of stances, sharing, and distributing information about the virus. Social media provide a platform where anybody can reveal his/her point of view, concern, question. Unlike traditional media which has mostly informative function, social media is the platform for dialogue. Johnson \& Kaye (2004) found that that credibility is higher for blogs in comparison with traditional media like television. The credibility stems from the idea that the author, who is the source of information, have personally experienced what he or she is writing about. Additionally, other users can edit, share and comment on the information available on social media, which allows for verification of the data's credibility. That may, however, result in adverse outcomes as well. Biased information and thus biased media, especially social media, can perpetuate a faulty understanding of the situation or worse, escalate the problem based on prejudice (Cho et al., 2020).

Information function would provide the latest updates about the virus in different countries, discoveries or attempts to fight it. However, overloading with the information may result in increasing publics' fear and anxiety levels. In 1976, Ball-Rokeach \& Defleur (1976) found that the public would turn to media to seek reliable information during crises. When people do not have access to real-time events or news or when the data is not valid enough, especially in outbreak times, they turn to social media to find out about the crisis (Oh et al., 2015). Findings on such infections as Avian flu (Fung et al., 2011), H1N1 flu (Oh et al., 2015) and COVID-19 (Manzoor \& Safdar, 2020) pointed out that mass media impact the public risk perception to a great extent.

Mass media has many roles, such as bonding and diversion functions. However, from the latest pandemic outbreak, information, interpretation and instructive functions were of the highest value. Usually, the instructive functions are fulfilled by certain channels on television or dedicated programs, but interestingly that during COVID-19, new social media are widely used instead - to instruct and remind people about wearing the masks, how to wash hands, how to behave in public and to stay at home. Government authorities have also emphasized social media channels and television 
to increase people's awareness of pandemic of 2019 (Addi et al., 2020). The social media channels and television can be used effectively to inform people about the consequences of virus and what measures they should take to protect themselves. Social media channels became very useful in information communication, particularly in countries where it is impossible to reach people due to the remote location. Manzoor \& Safdar (2020) explored to which extent the information in media impacted Pakistani people and what opinions toward the COVID-19 they hold. Media provided a significant amount of data prompting the public's mental health negative implications. The researchers conducted interviews and found that many consider the virus extremely dangerous, resulting in anxiety, panic and depression. Nonetheless, they also found high awareness of people about the necessity and importance of preventive measures. Media and their broadcasted instructions can account for the dominant understanding.

\section{Risk Perception}

Mass media always had great importance in shaping public risk perception. It was recognized long ago and confirmed by several authors (Snyder \& Rouse, 1995; Bomlitz \& Brezis, 2008). Additionally, lack of masks medical equipment, slow development of the vaccine can even worsen the situation. People's immune system that was developing and adopting through ages can fight ordinary flue and seasonal cold with or without additional medical treatment, unlike COVID-19, that causes lungs damage and breathing problems.

$\mathrm{Ng}$ et al. (2018) proposed that exposure to social media helps heighten society's risk perception far more than conventional media coverage. While antecedent studies focused on traditional media sources, contemporary research pays closer attention to the information obtained via social media, taking into account the current fast information exchange trend. Social media is regarded as one of the most well-known and affordable ways of obtaining information which can be accessed easily and freely by the members of the public. However, its effects and the information that media are transmitting may impact people in different ways. As per Kasperson et al. (1988) and their proposed Social Amplification of Risk Framework, the means of social media might function as a "social amplification station" in shaping the social experience of a hazard and social perception of risk, through either the amplification (Ali et al., 2019) or reduction of the public risk perception (Kasperson et al., 1988).

According to a few authors like Altheide \& Michalowski (1999) and Raude et al., (2010), predictions can be made about people's attributing the importance to the virus according to the intensity of fear they feel. Giving the extensive media coverage about the virus, the latter authors confirmed that effect on the example of H1N1 in France and in particular in the willingness to accept the vaccination.

In this regard, it should be mentioned that the fear of individuals is largely influenced by the media. When people are directly exposed to media information, they become even more afraid. The role of media in predicting the fear among Norwegians was confirmed by Hansen (2009) during the SARS period. The results found by Van Den Bulck \& Custers (2009) confirms that the fear of the virus, like H5N1, may occur much earlier than the virus itself.

\section{Fear Drive Model}

Turner \& Underhill (2012) have found that emotions not only transform the behavioural outcomes, but they also boost preventive behaviours through risk perception. Moreover, different emotions create distinctive action trends (Lazarus, 1991). The capability of emotion to make people act in one way or another is dictated by an action tendency, and this ability helps tackle the issue generating the specific feeling (Frijda, 1986). For instance, fright might elicit either problemavoiding or problem-solving behaviour. Both aim to prevent a frightening event from happening (Lazarus, 1991; Frijda, 1986). However, per Yang \& Chu (2018), fear can serve two kinds of functions. First is increasing the alertness of people towards the possibility and harshness of hazards and consequently better ability to cope with them. The second is barring the involvement in behaviour, especially when the fear is too intense.

Janis (1967) suggested the inverted U-shaped Fear Drive Model defines various responses of people to fear. Based on this model, the fright in a modest amount may generate a motivational condition to deal with the risk. In contrast, too increased/decreased levels of fear might prevent people from taking part in such behaviours. Although the previous literature complies with the Fear Drive Model, recent studies have suggested that the interconnected positive fear influences preventive measures (LaTour \& Tanner, 2003, Hartmann et al., 2014, Ali et al., 2019). To illustrate this, the authors manifested intertwined connection between fear and preventive behaviours in the events of radon gas contamination. Also, Hartmann et al. (2014) acknowledge that when humans are more afraid of environmental hazards, their chances of participation in pro-environmental behaviours are higher. Yet, the correlation between anxiety and preventive actions might be heavily dependent on the circumstances of fear. 


\section{Self-Determination Theory}

The self-determination theory covers the spectrum of motivation, distinguishing between external and internal stimuli. Following the basic tenets of the Self-determination theory, there are few fundamental psychological needs inherent to human beings. Such is the need for autonomy, competence and relatedness, and individuals often engage in behaviours that facilitate the fulfilment of elementary needs based on diverse motivations. Cognitive Evaluation Theory (CET), another branch of Self-determination theory, posits internal and external events influence intrinsic and extrinsic motivation (Deci \& Ryan, 1990). A dichotomy was often posed concerning intrinsic and extrinsic motivation. The former supports the exercise of the behaviour's inherent satisfaction derived from engaging in it or the supreme value one appraises to such behaviour. Extrinsic motivation guides the behaviour with the expectation of external rewards, and incentives are always reducible to innate needs. In the context of disease prevention, extrinsic motivation may be due to one's drive to feel competent while dealing with the environment, and people may also be motivated to comply with the norm in order to meet their need for social support and social networking or to avoid guilt, dangerous consequences and community judgement. Extrinsically motivated persons often exert behaviour because they were coerced or directed to do so. When externally regulated, one's behaviour is compulsory and not self-determined insofar, it is subjected to external requirements and norms. Contrary, introjection is another type of regulation, and it indicates that external requirements are internalized, meaning the behaviour is partially intentional. When a behaviour is introjected, internalization of external pressure is applied to the person through sanctions and self-discipline. On the other hand, identification driven behaviour is regarded as self-determined as the individual considers the outcomes extremely valuable. On the other end of the spectrum, integrated regulation means that required behavioural outcome is entirely correspondent to individual's sense of self, making the behaviour fully autonomous, and thus the fundamental need for autonomy is fulfilled.

\section{Stay at Home Intention, Perceived Locus of Causality (PLOC)}

The motivation to stay at home was explained through the concept of PLOC. After COVID-19 breakdown, China was the first country that had to implement lockdown inside the country. Further, stay at home campaign was introduced mainly by many countries to avoid spreading of the virus. Referring to Ryan \& Connell (1989), people's motivation to act on some stimuli can be explained by the perceived locus of causality (PLOC). Initially, the main idea of PLOC distinguished internal (personal) and external (impersonal) stimuli Heider 1958, however later it was developed into much broad and precise concept that measures external, intrinsic, introjected, integrated and identified regulation to capture the motivations and intentions behind the behaviour.

External stimuli were forced lockdown regime and stay at home policy, introduced by governments. To reduce the movements in the cities, France introduced a different system of fines if people violate lockdown rules, people in Russia needed a special document that allowed to go shopping, Uzbekistan had a curfew with police cars driving on the streets and asking people to stay at home, Sweden didn't implement lockdown, however massively spread stay at home campaign recommended by the government in social media.

Introjected stimuli were included as people's motivation to stay at home due to conscience feeling like guilt and shame if they violate the government's recommendations. Here it is important to note the effect of social media, which is used as the platform to show violators as well as people's disapproval and even anger toward others who violate stay-at-home recommendations. Videos of Russian people having a barbeque after lockdown policy and Swedish people visiting restaurants were disapproved by others.

Identifications reasons were based on personal motivations and values. From this perspective, people can have their motives to stay at home, such as fear for close people, the importance of being off with the family. Stay at home regime allowed many individuals distance working or distance studying. The new possibility occurred that many companies and especially educational organizations previously avoided. Individuals got the chance to stay at home and devote themselves more to their family. Where applicable, intrinsic motivations described as enjoyment to stay at home were also included as a part of PLOC.

It is important to note that the cultural background of people in each country. For instance, people in Scandinavia kept social distance even before pandemic started, compared to Asian countries where people used to shake hands, hug each 
other and even kiss when they meet. Consequently, the integration of stay at the home policy was different in different countries. Sweden provided recommendations for social distancing and ban on the social gathering of more than 50 people, believing that mandatory measures are unnecessary. While in Asian countries, especially with a big population per square meter like Uzbekistan such measures were much stricter. It was obligatory for people to stay at home since public transport was suspended.

\section{Cultivation Theory and Social Media}

Cultivation theory first introduced over 40 years and later expanded by Gerbner \& Gross (1976) initially presents that people exposed to media would perceive the world through the prism presented by media. Most studies focus on the television as the main media source (Singer \& Yankelovich, 1992; Besley \& Shanahan, 2005). However, it is interesting to explore the influence of new media in the form of social media.

$\mathrm{Ng}$ et al. (2018) propose that exposure to social media helps heighten risk perception of society far more than conventional media coverage. While antecedent studies focused on traditional media sources, contemporary researchers paid closer attention to the information received from social media, taking into account the current trend of fast information exchange.

The cultivation theory explains that time spent on media impacts people's perception in a more significant effect compared to people who spend less time on media. They would even start living in so-called" media reality" with Mean World Syndrome ignoring the real-life facts and believing that the world and people are more dangerous than they are (Gerbner \& Gross, 1976). It is interesting if people concerning the recent pandemic events start living with the Sick World Syndrome and if that can be considered not only from a wrong side but also as a catalyst toward preventive measures. Studies done by (Mesch et al., 2013) found that the fear of being infected by H1N1 was positively correlated with the time spent in social media. Similar findings were done by Garfin et al. (2020) in terms of COVID-19. The increased stress and anxiety may lead to overreaction and wrong self-health estimation and, thus, serious health resources problem on countries' scale. Social media for news consumption is particularly well spread among the young generation who tend to be less obedient in following restrictions and precautionary measures. According to the findings by Raude et al. (2010), the youngest groups aged from 16 to 24 were the last to be vaccinated against the H1N1 virus.

The cultivation theory was also further expanded by numerous researchers that not only media exposure but also the content (Schiappa et al., 2006), diversity of television exposure (Dahlstrom \& Scheufele, 2010) can trigger cultivation effects. The latter found that diversity of exposure leads to the increased concern for ecological threats in general and even after considering the demographical variables. In terms of social media, companies are usually turning toward social media channels to promote their products better. Social media metrics can show the real results of promoted campaigns such as engagement, conversion, response rate, reach. Moreover, social media tools allow to customize and target the content to a certain audience to achieve better results. If companies can do that in order to enhance better sales of their products, it is, therefore, interesting why not use it for creating health awareness among the population. Public agencies of some countries use social media for that purpose. And people would receive targeted messages and instructions in social media in their native language.

\section{Conclusion}

Various national and global media outlets have daily reports and updates concerning the Coronavirus pandemics, reporting on the number of infected, quarantined, hospitalized and death instances, and new policy measures and restrictions introduced and implemented. While traditional media still plays a significant role in shaping risk perception, social media can be considered even more influential. Unlike its traditional counterparts which are mostly informative and unidirectional, contemporary media is interactive. Interaction presupposes the exchange of ideas, stances, theories, fears, and conspiracies and misinformation. This feature can be both beneficial and detrimental, depending on the usage and regulation of fake news. Social media platforms' immense potential in forming peoples' opinions and risk perceptions calls for crisis communication management on the part of governments, Security and Reconnaissance staff, and policymakers. Joining forces with leading scientists from various domains, such as epidemiology, governance, economy and psychology, they should create strong, potent and persuasive content tailored to fit the social media format and strategically lunch healthcare protection campaigns. The news should deliver the message clearly and reliably, following the suggestions of the EPPM model standard. In the instance of the 'Stay at home' campaign that promotes abiding with social distancing recommendations, experts should combine appropriate images, data and information according to feardriving model, and provide reliable guidelines concerning protective measures citizens can take to ensure safety. Apart 
from freight inciting strategy, propaganda should focus on educating and emphasizing the effectiveness of complying with the norm. The efficiency of social restriction should be demonstrated by presenting social media users with data illustrating the decrease in infection instances. Social media can also be used to examine public opinions concerning novel policy measures and gather data on citizens' adhering to restrictions in anonymous public opinion polling. Governments should strive to become a reliable source of information so that citizens do not form conclusions based on unreliable and incorrect sources such as speculations of other social media users.

\section{References}

- Ali, K., Zain-ul-abdin, K., Li, C., Johns, L., Ali, A. A., \& Carcioppolo, N. (2019). Viruses Going Viral: Impact of Fear-Arousing Sensationalist Social Media Messages on User Engagement. Science Communication. CrossRef

- Altheide, D. L., \& Michalowski, R. S. (1999). Fear in the news: A discourse of control. Sociological Quarterly. CrossRef

- Ball-Rokeach, S. J., \& Defleur, M. L. (1976). A Dependency Model of Mass-Media Effects. Communication Research. $\underline{\text { CrossRef }}$

- Besley, J. C., \& Shanahan, J. (2005). Media attention and exposure in relation to support for agricultural biotechnology. Science Communication. $\underline{\text { CrossRef }}$

- Bomlitz, L. J., \& Brezis, M. (2008). Misrepresentation of health risks by mass media. Journal of Public Health. CrossRef

- Cho, H., Li, W., Cannon, J., Lopez, R., \& Song, C. (2020). Testing three explanations for stigmatization of people of Asian descent during COVID-19: maladaptive coping, biased media use, or racial prejudice? Ethnicity and Health, $0(0), 1-16 . \underline{\text { CrossRef }}$

- Chong, M., \& Choy, M. (2018). The Social Amplification of Haze-Related Risks on the Internet. Health Communication. $\underline{\text { CrossRef }}$

- Dahlstrom, M. F., \& Scheufele, D. A. (2010). Diversity of television exposure and its association with the cultivation of concern for environmental risks. Environmental Communication, 4(1), 54-65. CrossRef

- Dunlop, S., Wakefield, M., \& Kashima, Y. (2008). Can you feel it? Negative emotion, risk, and narrative in health communication. Media Psychology. CrossRef

- Etim, A. E., Uzonna, I., \& Worgu Steve, C. (2018). Social media usage and firm performance: Reflections from the Nigerian telecommunication sector. International Journal of Management Science and Business Administration, 4(6), 7-16. CrossRef

- France24. (2020, April 8). Coronavirus spotlights Swedish segregation. Live news https://www.france24.com/en/20200418-coronavirus-spotlights-swedish-segregation

- Frijda, N. H. (1986). The emotions: Studies in emotion and social interaction. Cambridge University Press.

- Fung, T. K. F., Namkoong, K., \& Brossard, D. (2011). Media, social proximity, and risk: A comparative analysis of newspaper coverage of avian flu in Hong Kong and in the United States. Journal of Health Communication. CrossRef

- Garfin, D. R., Silver, R. C., \& Holman, E. A. (2020). The novel coronavirus (COVID-2019) outbreak: Amplification of public health consequences by media exposure. In Health Psychology. CrossRef

- Gerbner, G., \& Gross, L. (1976). Living With Television: The Violence Profile. Journal of Communication. CrossRef

- Godinic, D., Obrenovic, B., \& Khudaykulov, A. (2020). Effects of Economic Uncertainty on Mental Health in the COVID-19 Pandemic Context: Social Identity Disturbance, Job Uncertainty and Psychological Well-Being Model. International Journal of Innovation and Economic Development, 6(1), 61-74. CrossRef

- Hansen, K. F. (2009). Approaching doomsday: How SARS was presented in the Norwegian media. Journal of Risk Research. CrossRef

- Hartmann, P., Apaolaza, V., D'souza, C., Barrutia, J. M., \& Echebarria, C. (2014). Environmental threat appeals in green advertising: The role of fear arousal and coping efficacy. International Journal of Advertising. CrossRef

- Heider, F. (1958) The Psychology of Interpersonal Relations. New York: John Wiley \& Sons. CrossRef

- Janis, I. L. (1967). Effects of Fear Arousal on Attitude Change: Recent Developments in Theory and Experimental Research1. Advances in Experimental Social Psychology. CrossRef

- Johnson, T. J., \& Kaye, B. K. (2004). Wag the blog: How reliance on traditional media and the Internet influence credibility perceptions of Weblogs among blog users. Journalism and Mass Communication Quarterly, 81(3), 622642. CrossRef

- Kasperson, R. E., Renn, O., Slovic, P., Brown, H. S., Emel, J., Goble, R., Kasperson, J. X., \& Ratick, S. (1988). The Social Amplification of Risk: A Conceptual Framework. Risk Analysis. CrossRef

- LaTour, M. S., \& Tanner, J. F. (2003). Radon: Appealing to Our Fears. Psychology and Marketing. $\underline{\text { CrossRef }}$ 
- Lazarus, R. S. (1991). Cognition and motivation in emotion. American Psychologist. CrossRef

- Manzoor, S., \& Safdar, A. (2020). Cultivation of Fear Through Media: Analysis to Reveal Relationship between Perception about COVID 19 and Socio-economic Background of Media Consumers. Review of Economics and Development Studies, 6(2), 317-328. CrossRef

- Ng, Y. J., Yang, Z. J., \& Vishwanath, A. (2018). To fear or not to fear? Applying the social amplification of risk framework on two environmental health risks in Singapore. Journal of Risk Research, 21(12), 1487-1501. CrossRef

- Obrenovic, B., Du, J., Godinic, D., Tsoy, D., Khan, M. A. S., \& Jakhongirov, I. (2020). Sustaining enterprise operations and productivity during the COVID-19 pandemic:"Enterprise Effectiveness and Sustainability Model". Sustainability, 12(15), 5981. CrossRef

- Oh, S. H., Paek, H. J., \& Hove, T. (2015). Cognitive and emotional dimensions of perceived risk characteristics, genre-specific media effects, and risk perceptions: the case of H1N1 influenza in South Korea. Asian Journal of Communication, 25(1), 14-32. CrossRef

- Paek, H. J., Oh, S. H., \& Hove, T. (2016). How Fear-Arousing News Messages Affect Risk Perceptions and Intention to Talk About Risk. Health Communication. CrossRef

- Schiappa, E., Hewes, D. E., \& Gregg, P. B. (2006). Can one TV show make a difference? Will \& Grace and the parasocial contact hypothesis. Journal of Homosexuality, 51(4), 15-37. CrossRef

- Schwarz, N., \& Clore, G. L. (1983). Mood, misattribution, and judgments of well-being: Informative and directive functions of affective states. Journal of Personality and Social Psychology. CrossRef

- Silvia, S. (2019). The Importance of Social Media and Digital Marketing to Attract Millennials' Behavior as a Consumer. Marketing, 4(2). CrossRef

- Singer, E., \& Yankelovich, D. (1992). Coming to Public Judgment: Making Democracy Work in a Complex World. Contemporary Sociology. $\underline{\text { CrossRef }}$

- Slovic, P., Finucane, M. L., Peters, E., \& MacGregor, D. G. (2007). The affect heuristic. European Journal of Operational Research. $\underline{\text { CrossRef }}$

- Snyder, L. B., \& Rouse, R. A. (1995). The Media Can Have More Than an Impersonal Impact: The Case of AIDS Risk Perceptions and Behavior. Health Communication. CrossRef

- Turner, M. M., \& Underhill, J. C. (2012). Motivating Emergency Preparedness Behaviors: The Differential Effects of Guilt Appeals and Actually Anticipating Guilty Feelings. Communication Quarterly. CrossRef

- Van Den Bulck, J., \& Custers, K. (2009). Television exposure is related to fear of avian flu, an Ecological Study across 23 member states of the European Union. European Journal of Public Health. CrossRef

- WHO. (2020). Novel Coronavirus. Situation Report - 205, 205(6), 1-19..

- Yang, J. Z., \& Chu, H. (2018). Who is afraid of the Ebola outbreak? The influence of discrete emotions on risk perception. Journal of Risk Research. $\underline{\text { CrossRef }}$ 